\title{
Voluntary policies on checkout foods and healthfulness of foods displayed at, or near, supermarket checkout areas: a cross-sectional survey
}

\author{
Chi Ching Vivian Lam ${ }^{1}$, Katrine T Ejlerskov ${ }^{2}$, Martin White ${ }^{2}$ and Jean Adams ${ }^{2, *}$ \\ 'Department of Public Health \& Primary Care, Institute of Public Health, University of Cambridge, Cambridge, UK: \\ ${ }^{2}$ Centre for Diet \& Activity Research, MRC Epidemiology Unit, University of Cambridge, Box 285 Institute of \\ Metabolic Science, Cambridge Biomedical Campus, Cambridge CB2 OQQ, UK
}

Submitted 29 March 2018: Final revision received 20 July 2018: Accepted 23 August 2018: First published online 12 October 2018

\begin{abstract}
Objective: To determine if voluntary policies on supermarket checkout foods are associated with a difference in the healthfulness of foods displayed at, or near, supermarket checkout areas.

Design: Cross-sectional survey of foods at, or near, supermarket checkouts categorised as less healthy or not according to the Food Standards Agency's Nutrient Profiling Model.

Setting: One city in Eastern England (population about 125000).

Subjects: All stores in nine supermarket groups open for business in June-July 2017 in the study city. Supermarket checkout food policies were categorised as clear and consistent, vague or inconsistent, or none.

Results: In thirty-three stores, 11434 checkout food exposures were recorded, of which 8010 (70.1\%) were less healthy; and 2558 foods in areas near checkouts, of which 1769 (69.2\%) were less healthy. After adjusting for a marker of store size, the odds of a checkout food exposure being 'less healthy' was lower in stores with vague or inconsistent checkout policies (OR $=0.63 ; 95 \% \mathrm{CI} 0.49,0.80)$ and in stores with clear and consistent checkout policies (OR =0.33; $95 \%$ CI 0.24, 0.45), compared with no policy. There was no difference in the odds of foods near, but not at, checkouts being less healthy according to checkout food policy.

Conclusions: Supermarket checkout food policies were associated with lower odds of checkout foods but not foods near, but not at, checkouts being less healthy. Further research is required to explore impacts on purchasing and consumption.
\end{abstract}

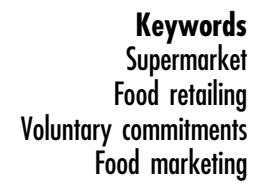

Keywords

Supermarket

commitments Food marketing
Exposure to energy-dense, nutrient-poor foods and drinks contributes to the development of obesity ${ }^{(1)}$. One potential source of such foods, which has gained media ${ }^{(2)}$, campaign group $^{(3,4)}$ and research ${ }^{(5-10)}$ attention, is supermarket checkouts.

Globally, supermarket checkout foods tend to be less healthy and positioned to attract children ${ }^{(5-9)}$. Foods at checkouts can lead to impulse purchases and child purchasing requests ${ }^{(8,11,12)}$, which parents can find hard to resist $^{(4,13)}$. The balance of healthier to less healthy checkout foods influences purchasing, with healthier foods being more likely to be selected when they dominate $^{(14)}$.

A number of UK supermarkets have policies limiting the display of 'less healthy' foods at checkouts. A large scoping review on retail micro-environments in 2013 identified that changing the availability of healthy foods can alter purchasing ${ }^{(15)}$; but no studies on checkout foods were identified. Since then, a small number of researcher-led studies have reported mixed effects of changing supermarket checkout foods ${ }^{(13,16-19)}$. These inconsistent results are likely due to variations in the types of products targeted and the level of implementation achieved. The only previous study we are aware of on the impact of supermarket-led checkout food policies found that stores with policies were less likely to display foods at checkouts than stores without policies; and that the foods displayed were more likely to be 'healthier ${ }^{\text {(20) }}$. That study also found that supermarkets adhered well to their checkout food policies, especially if they were clear and consistent.

In the UK, supermarket checkout food policies currently take the form of voluntary commitments. There is substantial 
scepticism about the potential for such commitments to lead to meaningful public health change ${ }^{(21-23)}$. This is fuelled in part by evidence that previous voluntary agreements between government and food industry organisations tend to focus on less effective intervention strategies and reflect actions that companies were already doing, or planning to $\mathrm{do}$, at the time agreements were made $\mathrm{21,24-26)}^{(2}$

While current UK supermarket checkout food policies are voluntary commitments made by supermarkets, they are not voluntary agreements between food retailers and government $^{(27)}$. Instead they are retailer-led, self-regulatory, voluntary actions without any government involvement. Several reasons why industries self-regulate have been described $^{(28)}$. In the case of supermarket checkout foods, the most likely is the threat to public relations associated with less healthy checkout foods, following campaigns that have highlighted how difficult shoppers find it to resist child purchasing requests for checkout foods ${ }^{(3,4,13)}$.

Removing less healthy foods from supermarket checkouts may, therefore, improve the customer experience, as well as public health. But if it also leads to decreased sales this could be at odds with supermarkets' commercial interests. When commercial and public health interests are in conflict, there is an incentive for self-regulatory policies to be weakly conceived and poorly enforced ${ }^{(23,28)}$. One way in which supermarkets might undermine checkout food policies to avoid commercial impacts is to display less healthy checkout-type foods in areas near, but not at, checkouts. These areas include aisle ends opposite checkouts - another area associated with impulse purchases, with about $40 \%$ of purchases estimated to be made from aisle ends ${ }^{(29)}$.

The aim of the current study was to determine if the presence and nature of voluntary policies on supermarket checkout foods were associated with a difference in the healthfulness of foods displayed at, or near, supermarket checkout areas.

\section{Methods}

We conducted a cross-sectional survey in June-July 2017 of foods at, or near, supermarket checkouts in one city in Eastern England with a population of about 125000 . The city is less deprived and more healthy than England as a whole $^{(30)}$ and was chosen for pragmatic reasons.

\section{Supermarket and store selection}

We included all stores open for business in June-July 2017 located within the administrative boundaries of the study city and that belonged to one of the nine supermarket groups that together account for more than $90 \%$ of the UK grocery market ${ }^{(31)}$. Thirty-two stores were identified via the 'store locater' function on supermarket group websites. During data collection, one additional store was identified and included. Two of the nine supermarket groups did not have stores in the study city. As our intention was to study the associations between checkout food policies and foods displayed, rather than 'name and shame' particular supermarket groups, we have chosen not to identify specific supermarket groups in the 'Results' section of the present paper.

\section{Foods at, or near, supermarket checkout areas}

We defined supermarket checkout areas as any area that customers must pass through to pay for purchases ${ }^{(10,20)}$. All foods and non-alcoholic drinks (collectively referred to as 'foods' hereafter) within the researcher's arm's reach $(\sim 0.5 \mathrm{~m})$ of these areas were considered foods at checkout areas. We defined areas near to checkout areas as any area within five paces $(\sim 3.5 \mathrm{~m})$ of any part of a checkout area that did not meet the definition of checkout areas. Foods within arm's reach of these areas were considered foods near, but not at, checkouts. Alcoholic drinks were excluded as these are excluded by the policy-relevant tool used to determined 'healthfulness' of foods described below.

We used the concept of 'checkout journeys' to quantify 'checkout food exposures' ${ }^{(10,20)}$. A checkout journey was defined as a route through a checkout area (as defined above). We first determined all possible checkout journeys in each store. We then calculated checkout food exposures as the sum of the number different food lines in each possible checkout journey in each store. In many stores, shared queuing areas leading to multiple payment points make numerous different checkout journeys possible. Any food lines in shared queuing areas were multiple counted to reflect the total number of possible checkout journeys through the shared area. For example, chewing gum displayed in a shared queuing area leading to five payment points was counted five times; whereas chewing gum displayed at a single payment point was counted once.

Foods near, but not at, checkouts were only counted once as the number of possible customer paths past these displays was indeterminable (although likely to be greater than one).

\section{Data collection}

Data collection was conducted by one researcher (C.C.V. L.). The researcher visited all study stores and recorded the number of checkouts in each store, and all food lines displayed at, or near, checkout areas. Only the range of food lines was recorded, not the number of units (or 'facings') present. This reflects previous approaches ${ }^{(10,20)}$, and minimised the intrusiveness of data collection and any disruption to stores. Where the same food line was displayed in a range of package sizes, only the presence of the line was recorded, not the package sizes. Thus, if a particular brand of salt \& vinegar potato crisps was displayed in small and large packages, only the presence of that brand and flavour of potato crisps was recorded. 
Where similar products were present in a number of flavour variants, all variants were recorded. Thus, if both salt \& vinegar and cheese \& onion flavours of the same brand of potato crisps were displayed, both flavours were recorded.

Data were recorded in-store using a mobile telephone voice recorder. Recordings were downloaded and transcribed within three days of recording. This method has previously been found to have high inter-rater reliability $^{(10)}$. To confirm this, a second researcher (E.T.-M.) repeated data collection independently in one study store selected for convenience. There was 95\% agreement between researchers on products recorded.

\section{Healthfulness of foods at, or near, supermarket checkout areas}

All foods identified during data collection were categorised as 'less healthy' or 'healthier' using the Food Standards Agency's Nutrient Profiling Model ${ }^{(32)}$. This model balances 'positive' and 'negative' nutrients and food components to arrive at an overall score. Standard cut-offs are used to determine if a food is less healthy. The model is used to determine which foods can be advertised to children on UK television and has reasonable specificity and sensitivity ${ }^{(33)}$.

To determine Nutrient Profiling Model scores, nutritional information on observed foods was obtained from one of three sources. We gave preference to information published on manufacturer's websites, followed by UK supermarket websites, followed by an online crowdsourced database of branded foods (https://www.world .openfoodfacts.org). When no branded data from any of these sources could be found, we used data from an equivalent unbranded product in the Composition of Foods Integrated Dataset ${ }^{(34)}$.

\section{Presence and nature of supermarket checkout food policies}

We used data collected in May-September 2017 to determine the presence and nature of supermarket checkout food policies ${ }^{(20)}$. We searched the annual reports and webpages of included supermarket groups for information on their checkout food policies and contacted supermarkets' customer services for further information as needed. When information was not available by these methods, we used information from newspaper articles or other secondary sources.

We categorised checkout food policies into two groups $^{(20)}$ : clear and consistent policies were those that provided clear information on inappropriate and appropriate checkout foods and applied consistently to all checkouts in stores; vague or inconsistent polices provided vaguer product information or did not apply consistently to all checkouts (or both). One supermarket group had different policies for different store formats (i.e. convenience stores $v$. large hypermarkets). Checkout food policies of included supermarket groups are summarised in Table 1.

\section{Data analysis}

We conducted analysis at the store level ( $n$ 33) with the outcome of interest being the proportion of checkout food exposures or foods near, but not at, checkouts which was less healthy. We used log-binomial regression to determine the odds of a checkout food exposure or food near, but not at, a checkout being less healthy in stores with clear and consistent, or vague or inconsistent checkout food policies, compared with those with no checkout food policy. This approach has been recommended for modelling dependent variables which, as here, are proportions ${ }^{(35)}$. Smaller stores may be more cramped making it harder to impose checkout food policies. As such, we adjusted models for the total number of checkouts in each store (a proxy for store size). Standard errors, and hence $95 \%$ CI, were adjusted for clustering of stores at the supermarket group level. There were no stores with no food at checkouts. In stores where there was no food near, but not at, checkouts ( $n$ 3) these stores were excluded from the relevant analyses.

\section{Etbics}

In line with current guidance, we did not seek ethical approval for the present study which did not include any human, or animal, participants. Store managers were not explicitly asked permission for observations to take place. At no point was the researcher challenged by a member of store staff.

\section{Results}

All thirty-three stores, in seven supermarket groups, identified as meeting the inclusion criteria were included. Food was found at one or more checkouts in all stores, but three stores did not have any food in areas near checkouts.

We identified 11434 checkout food exposures, of which 8010 (70.1\%) were less healthy; and 2558 foods near, but not at, checkouts, of which 1769 (69.2\%) were less healthy. Table 2 provides information on the number of stores, checkouts, checkout food exposures and foods near, but not at, checkouts by supermarket group and format.

In stores with no checkout food policy, $72.4 \%$ of checkout food exposures were less healthy, $75 \cdot 1 \%$ were less healthy in stores with vague or inconsistent policies, and $51.8 \%$ were less healthy in stores with clear and consistent policies (Table 2). After adjusting for the number of checkouts in stores, the odds of a checkout food exposure being less healthy was lower in stores with vague or inconsistent policies compared with no policy $(\mathrm{OR}=0.63 ; 95 \% \mathrm{CI} 0.49,0 \cdot 80)$ and between stores with 
clear and consistent $v$. no policy (OR $=0.33 ; 95 \%$ CI 0.24 , $0 \cdot 45$; Table 3).

In total, $72.5 \%$ of foods near, but not at, checkouts were less healthy in stores with no checkout food policy, $68.9 \%$ in those with vague or inconsistent policies, and $63.2 \%$ in those with clear and consistent policies (Table 2). After adjustment for the number of checkouts in stores, there was no evidence of a difference in the odds of foods near, but not at, checkouts being less healthy according to checkout food policy type (Table 3).

\section{Discussion}

\section{Summary of main findings}

We conducted a census of foods at, and near, supermarket checkouts in one city in Eastern England. This is the first assessment of foods near, but not at, checkouts we are aware of, and the first to explore associations between difference supermarket checkout policies and these foods. After adjusting for a marker of store size, we found that the proportion of checkout food exposures that were 'less healthy' was lowest in stores with clear and consistent checkout food policies, intermediate in stores with vague or inconsistent policies and highest in stores with no policy. There was no difference in the proportion of less healthy foods near, but not at, checkouts according to checkout food policy.

\section{Strengths and limitations of methods}

We conducted a census of all supermarkets in one city, eliminating any internal sampling bias. However, the study city is not representative of the UK in terms of deprivation and health status of residents, or the supermarket groups present. This may limit external validity. As it is unlikely that the impact of checkout food policies on foods at, or near, checkouts varies between cities, the findings should be generalizable across the seven supermarket groups included. Together these account for around $80 \%$ of the UK grocery market ${ }^{(31)}$.

We made substantial attempts to collect accurate data on supermarkets' checkout food policies. However, in some cases we were forced to rely on secondary sources. This may introduce error. The data collection method has previously been reported to have high inter-rater reliability $^{(10)}$ and we confirmed this.

There are likely to be seasonal variations in foods displayed at, and near, checkouts. There may also be seasonal variations in the impact of supermarket checkout food policies on what foods are displayed. For example, if supermarkets place particular emphasis on particular seasonal promotions, these may override checkout food policies at some times of the year.

We used the Food Standards Agency's Nutrient Profiling Model to classify foods as 'less healthy' or 'healthier',(32).

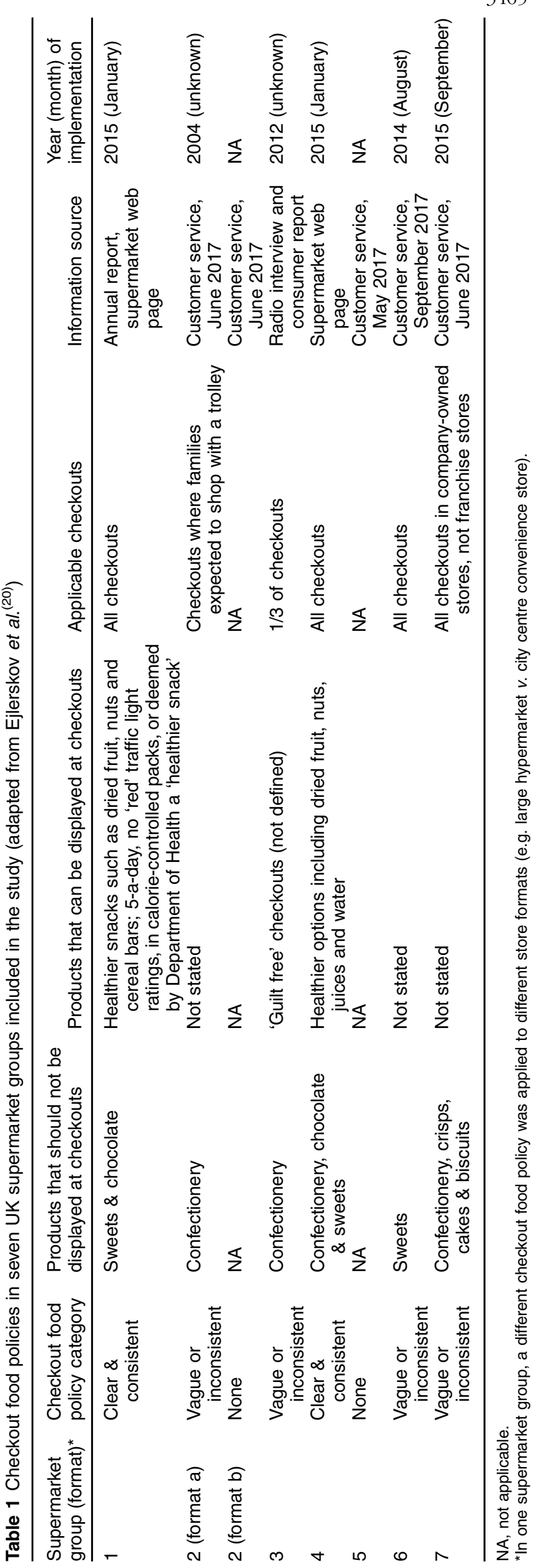


This is policy-relevant to the UK context. While objective, it does not necessarily reflect the intention of supermarket checkout food policies, or the full spectrum of healthfulness of foods. Nor does it include alcohol.

Our data reflect what foods are displayed, not necessarily what customers buy or consume. No account was taken of the number of 'facings' (or units) of different products displayed or how much shelf space each product accounted for. This may also influence purchasing and consumption. Further research is required to explore the impact of checkout food policies on food purchasing and consumption. While we weighted foods displayed at checkouts according to an indicator of customer exposure, there was no comparable way to do the same for foods in areas near checkouts.

Our analyses focus on the proportion of foods at, or near, checkouts that was less healthy. This does not take into account that there were no foods at some checkouts and in some stores that there were no foods near, but not at, checkouts. It is possible that the absence of foods in these areas represents the 'healthiest' condition.

\section{Comparison of findings with previous studies}

Across all stores, we found that $70 \%$ of checkout food exposures were for less healthy foods. This is comparable to previous findings from supermarkets and non-food stores in the UK which revealed about $70-80 \%$ of checkout foods to be less healthy ${ }^{(5,10)}$. At least $70 \%$ of supermarket checkouts in Australia, Canada, Denmark, New Zealand, Sweden, the UK and the USA displayed at least one of confectionery, crisps, chocolate and soft drinks ${ }^{(6,8,9)}$.

In line with previous research ${ }^{(20)}$, we found some suggestion of a trend in the proportion of checkout foods that were less healthy from stores with clear and consistent, through vague or inconsistent, to no policies.

\section{Interpretation and implications of findings}

Overall, we found that a high proportion of foods at, and near, supermarket checkouts was 'less healthy' and would not be permitted to be advertised to children on UK television. This indicates a substantial public health concern.

However, the proportion of checkout food exposures that were less healthy was substantially lower in stores with checkout food policies than in those with no policy. This indicates that it may be possible to reduce the proportion of less healthy supermarket checkout food exposures, and that alternative foods appear to be available. However, our data are cross-sectional and it is not necessarily the case that it is the checkout food policies that are responsible for the differences seen. For example, supermarkets with healthier checkout foods originally may have been more likely to implement checkout food policies. It has been proposed that there should be 
Table 3 Odds ratios of checkout food exposures and foods near, but not at, checkouts being less healthy, by checkout food policy category, in a survey conducted in all stores $(n 33)$ in seven major UK supermarket groups open for business in one city in Eastern England, JuneJuly 2017

\begin{tabular}{|c|c|c|c|c|c|}
\hline \multirow[b]{2}{*}{ Variable } & \multirow[b]{2}{*}{ Level } & \multicolumn{2}{|c|}{$\begin{array}{c}\text { Proportion checkout food exposures } \\
\text { less healthy }\end{array}$} & \multicolumn{2}{|c|}{$\begin{array}{c}\text { Proportion foods near, but not at, checkouts } \\
\text { less healthy }\end{array}$} \\
\hline & & $\mathrm{OR}^{*}$ & $95 \% \mathrm{Cl}$ & $\mathrm{OR}^{*}$ & $95 \% \mathrm{Cl}$ \\
\hline \multirow[t]{3}{*}{ Checkout food policy category } & None & \multicolumn{2}{|c|}{ Reference } & \multicolumn{2}{|c|}{ Reference } \\
\hline & Vague or inconsistent & 0.63 & $0.49,0.80$ & 0.90 & $0.20,4.03$ \\
\hline & Clear and consistent & 0.33 & $0.24,0.45$ & 1.21 & $0.65,2.23$ \\
\hline Checkouts per store $(n)$ & & 1.01 & $0.99,1.05$ & 0.97 & $0.91,1.02$ \\
\hline
\end{tabular}

${ }^{*}$ Adjusted for clustering at the supermarket group (format) level.

government regulation on checkout foods, although no details have yet been developed ${ }^{(3,36)}$.

In addition to finding a lower proportion of less healthy checkout foods in stores with checkout food policies $v$. no policies, we found no difference in the proportion of less healthy foods near, but not at, checkouts across different checkout food policy groups. Thus, it appears that stores with policies are not undermining their checkout food policies by placing greater proportions of less healthy foods near checkouts to make up for any reductions in sales associated with removing them from checkouts. In contrast, previous research has found little evidence of public health gain from voluntary agreements between government and the food industry ${ }^{(21,27)}$ or from food industry self-regulation ${ }^{(22,28,37-39)}$ for public health benefit. One potential reason for this divergence is that checkout food policies are conceived by supermarkets as enhancing customers' shopping experience, rather than as a public health measure ${ }^{(13)}$. These policies thus converge, rather than conflict, with supermarkets' commercial interests and there is no incentive for supermarkets to undermine them ${ }^{(13,28)}$. Qualitative work exploring why supermarket groups adopt the checkout food policies they do may offer further insights for maximising the potential of retail selfregulation for public health gain. Further focus on 'winwin' policies with commercial as well as public health benefits may be fruitful, although it is not clear how common these are ${ }^{(23)}$.

As we did not analyse purchasing or consumption data, we cannot draw definitive conclusions on the public health impact of checkout food policies. Stores with fewer less healthy checkout food exposures may make up for this by aggressively marketing checkout-type foods elsewhere in store. Future research is required to explore these issues.

\section{Conclusions}

In a survey of all thirty-three branches of large UK supermarket retailers in one English city, we found that the proportion of less healthy checkout foods was lower in stores with checkout food policies. However, there was no difference in the proportion of foods near, but not at, checkouts that was less healthy by checkout food policy.
Further research is required to explore impacts on purchasing and consumption. All supermarket checkout food policies in the UK are voluntarily developed and adopted by retailers. Further research is required to determine why the presence of these self-regulatory efforts is associated with greater differences in outcomes than some other selfregulatory efforts to improve public health. Framing selfregulation with potential for public health gain in terms of commercial benefit may be one way of maximising the impacts of this approach.

\section{Acknowledgements}

Acknowledgements: The authors thank Eleanor TurnerMoss for conducting duplicate data collection in one store to determine inter-rater reliability. Financial support: J.A. and M.W. receive salary support from the Centre for Diet and Activity Research (CEDAR), a UK Clinical Research Collaboration (UKCRC) Public Health Research Centre of Excellence. Funding from the British Heart Foundation, Cancer Research UK, Economic and Social Research Council, Medical Research Council (MRC), the National Institute for Health Research and the Wellcome Trust, under the auspices of the UKCRC, is gratefully acknowledged (MRC grant number MR/K023187/1). The funders had no role in the design, analysis or writing of this article. C.C.V.L. was an MPhil student at the University of Cambridge when this work was undertaken. Conflict of interest: None. Authorship: J.A. and M.W. conceived the idea for the work. C.C.V.L. collected the data and wrote a preliminary report. C.C.V.L. and K.T.E. analysed the data. J.A. drafted the manuscript. All authors contributed to data interpretation and critically reviewed the final manuscript. Ethics of human subject participation: This research did not involve human subjects.

\section{References}

1. Butland B, Jebb S, Kopelman P et al. (2007) Foresight Tackling Obesities: Future Choices - Project Report. London: Government Office for Science.

2. Delmar-Morgan A (2013) Sweets at supermarket tills are 'fuelling obesity crisis'. The Independent, 16 September 
2013. https://www.independent.co.uk/life-style/health-andfamilies/health-news/sweets-at-supermarket-tills-are-fuel ling-obesity-crisis-8818094.html (accessed September 2018).

3. Children's Food Campaign (2012) Checkouts checked out how supermarkets and high street stores promote junk food to children and their parents. http://www.sustainweb.org/ publications/?id=212 (accessed August 2014).

4. safefood (2014) Safefood asks supermarkets to introduce healthier checkouts. http://www.safefood.eu/News/2014/ safefood-asks-supermarkets-to-introduce-healthier.aspx (accessed May 2014).

5. Horsley JA, Absalom KAR, Akiens EM et al. (2014) The proportion of unhealthy foodstuffs children are exposed to at the checkout of convenience supermarkets. Public Health Nutr 17, 2453-2458.

6. Thornton L, Cameron A, McNaughton S et al. (2012) The availability of snack food displays that may trigger impulse purchases in Melbourne supermarkets. BMC Public Health 12, 194.

7. Miller C, Bodor JN \& Rose D (2012) Measuring the food environment: a systematic technique for characterizing food stores using display counts. J Environ Public Health $\mathbf{2 0 1 2}$, 707860 .

8. Dixon H, Scully M \& Parkinson K (2006) Pester power: snackfoods displayed at supermarket checkouts in Melbourne, Australia. Health Promot J Aust 17, 124-127.

9. Thornton L, Cameron A, McNaughton S et al. (2013) Does the availability of snack foods in supermarkets vary internationally? Int J Behav Nutr Phys Act 10, 56.

10. Wright J, Kamp E, White $M$ et al. (2015) Food at checkouts in non-food stores: a cross-sectional study of a large indoor shopping mall. Public Health Nutr 18, 2486-2793.

11. Campbell S, James EL, Stacey FG et al. (2012) A mixedmethod examination of food marketing directed towards children in Australian supermarkets. Health Promot Int 29, 267-277.

12. Cohen DA \& Babey SH (2012) Candy at the cash register - a risk factor for obesity and chronic disease. $N$ Engl J Med 367, 1381-1383.

13. Winkler LL, Christensen U, Glumer C et al. (2016) Substituting sugar confectionery with fruit and healthy snacks at checkout - a win-win strategy for consumers and food stores? A study on consumer attitudes and sales effects of a healthy supermarket intervention. BMC Public Health 16, 1184.

14. van Kleef E, Otten K \& van Trijp HC (2012) Healthy snacks at the checkout counter: a lab and field study on the impact of shelf arrangement and assortment structure on consumer choices. BMC Public Health 12, 1072.

15. Hollands GJ, Shemilt I, Marteau TM et al. (2013) Altering micro-environments to change population health behaviour: towards an evidence base for choice architecture interventions. BMC Public Health 13, 1218.

16. Foster GD, Karpyn A, Wojtanowski AC et al. (2014) Placement and promotion strategies to increase sales of healthier products in supermarkets in low-income, ethnically diverse neighborhoods: a randomized controlled trial. Am J Clin Nutr 99, 1359-1368.

17. Sigurdsson V, Larsen NM \& Gunnarsson D (2011) An instore experimental analysis of consumers' selection of fruits and vegetables. Serv Ind J 31, 2587-2602.

18. Sigurdsson V, Larsen NM \& Gunnarsson D (2014) Healthy food products at the point of purchase: an in-store experimental analysis. J Appl Behav Anal 47, 151-154.

19. Kroese FM, Marchiori DR \& de Ridder DT (2016) Nudging healthy food choices: a field experiment at the train station. J Public Health (Oxf) 38, e133-e137.

20. Ejlerskov K, Stead M, Adamson A et al. (2018) The nature of UK supermarkets' policies on checkout food and associations with healthfulness and type of food displayed: a cross-sectional study. Int J Behav Nutr Phys Act 15, 52.

21. Gilmore AB, Savell E \& Collin J (2011) Public health, corporations and the New Responsibility Deal: promoting partnerships with vectors of disease? J Public Health (Oxf) 33, 2-4.

22. Hawkes C (2005) Self-regulation of food advertising: what it can, could and cannot do to discourage unhealthy eating habits among children. Nutr Bull 30, 374-382.

23. Stuckler D \& Nestle M (2012) Big food, food systems, and global health. PLoS Med 9, e1001242.

24. Knai C, Petticrew M, Durand MA et al. (2015) Has a publicprivate partnership resulted in action on healthier diets in England? An analysis of the Public Health Responsibility Deal food pledges. Food Policy 54, 1-10.

25. Durand MA, Petticrew M, Goulding L et al. (2015) An evaluation of the Public Health Responsibility Deal: informants' experiences and views of the development, implementation and achievements of a pledge-based, public-private partnership to improve population health in England. Health Policy 119, 1506-1514.

26. Bagwell S (2013) Healthier catering initiatives in London, UK: an effective tool for encouraging healthier consumption behaviour? Crit Public Health 24, 35-46.

27. Bryden A, Petticrew M, Mays N et al. (2013) Voluntary agreements between government and business - a scoping review of the literature with specific reference to the Public Health Responsibility Deal. Health Policy 110, 186-197.

28. Sharma LL, Teret SP \& Brownell KD (2010) The food industry and self-regulation: standards to promote success and to avoid public health failures. Am J Public Health 100, 240-246.

29. Sorensen H (2008) Long tail media in the store. J Advert Res 48, 329-338.

30. Public Health England (2017) Public Health Outcomes Framework. https://fingertips.phe.org.uk/profile/publichealth-outcomes-framework (accessed January 2018).

31. Kantar Worldpanel (2017) Grocery Market Share. https:// www.kantarworldpanel.com/en/grocery-market-share/greatbritain/snapshot/21.05.17/ (accessed June 2017).

32. Rayner M, Scarborough P, Boxer A et al. (2005) Nutrient Profiles: Development of Final Model. Final Report for the Food Standards Agency. Oxford: British Heart Foundation Health Promotion Research Group, Department of Public Health, University of Oxford.

33. Quinio C, Biltoft-Jensen A, De Henauw S et al. (2007) Comparison of different nutrient profiling schemes to a new reference method using dietary surveys. Eur J Nutr $\mathbf{4 6}$, $35-46$.

34. Public Health England (2015) Composition of foods integrated dataset (CoFID). https://www.gov.uk/government/ publications/composition-of-foods-integrated-dataset-cofid (accessed January 2018).

35. Papke L \& Wooldridge J (1996) Econometric methods for fractional response variables with an application to 401 (K) plan participation rates. I Appl Econometrics 11, 619-632.

36. Which? (2012) A taste for change? Food companies assessed for action to enable healthier choices. https://www.which. co.uk/documents/pdf/a-taste-for-change---which-briefing--responsibility-deal-445309.pdf (accessed September 2018).

37. Hawkes C \& Harris J (2011) An analysis of the content of food industry pledges on marketing to children. Public Health Nutr 14, 1403-1414.

38. Hawkes C \& Lobstein T (2011) Regulating the commercial promotion of food to children: a survey of actions worldwide. Int J Pediatr Obes 6, 83-94.

39. Adams J, Hennessy-Priest K, Ingimarsdóttir S et al. (2009) Food advertising during children's television in Canada and the UK. Arch Dis Child 94, 658-662. 